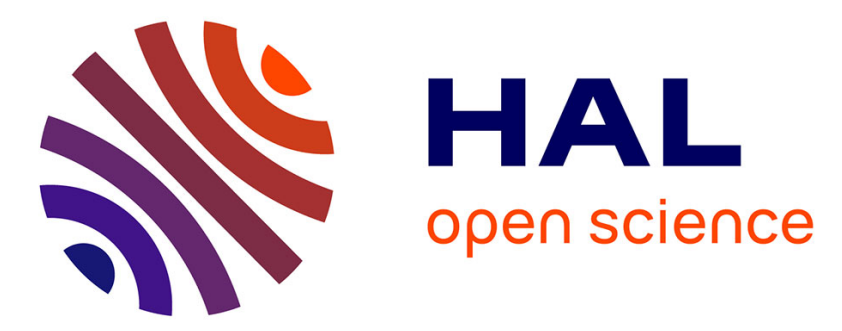

\title{
Quantitative 4D X-ray microtomography under extreme conditions: a case study on magma migration
}

Elena Giovenco, Jean-Philippe Perrillat, Eglantine Boulard, Andrew King, Nicolas Guignot, Yann Le Godec

\section{- To cite this version:}

Elena Giovenco, Jean-Philippe Perrillat, Eglantine Boulard, Andrew King, Nicolas Guignot, et al.. Quantitative 4D X-ray microtomography under extreme conditions: a case study on magma migration. Journal of Synchrotron Radiation, 2021, 28 (5), pp.1598-1609. 10.1107/S1600577521007049 . hal03411879

\author{
HAL Id: hal-03411879 \\ https://hal.science/hal-03411879
}

Submitted on 2 Nov 2021

HAL is a multi-disciplinary open access archive for the deposit and dissemination of scientific research documents, whether they are published or not. The documents may come from teaching and research institutions in France or abroad, or from public or private research centers.
L'archive ouverte pluridisciplinaire HAL, est destinée au dépôt et à la diffusion de documents scientifiques de niveau recherche, publiés ou non, émanant des établissements d'enseignement et de recherche français ou étrangers, des laboratoires publics ou privés. 


\title{
Quantitative 4D X-ray microtomography under extreme conditions: a case study on magma migration
}

Authors

\author{
Elena Giovenco $^{\mathrm{a} *}$, Jean-Philippe Perrillat ${ }^{\mathrm{a}}$, Eglantine Boulard ${ }^{\mathrm{b}}$, Andrew King ${ }^{\mathrm{c}}$, Nicolas \\ Guignot $^{\mathrm{c}}$ and Yann Le Godec ${ }^{\mathrm{b}}$ \\ a Laboratoire de Géologie de Lyon, UMR5276, Université Claude Bernard Lyon 1, CNRS, Ens de \\ Lyon, Villeurbanne, F-69622, France \\ ${ }^{\mathrm{b}}$ Institut de Minéralogie, de Physique des Matériaux et de Cosmochimie, UMR 7590, Sorbonne \\ Université, CNRS, MNHN, IRD, Paris, F-75252, France \\ ${ }^{c}$ Synchrotron Soleil, L'Orme des Merisiers, St Aubin, F-91192, France
}

Correspondence email: elena.giovenco@univ-lyon1.fr

Synopsis A practical step-by-step guide from CT images collection, reconstruction to quantitative analysis to account for the constraints imposed by high-pressure and temperature experimentation.

\begin{abstract}
X-ray computed tomography (XCT) is a well-known method for three-dimensional characterization of materials that established as a powerful tool in high-pressure/high-temperature research. The optimization of synchrotron beamlines and the development of fast high efficiency detectors now allow the addition of a temporal dimension to tomography studies under extreme conditions. Here, we present the experimental set-up developed at the PSICHE beamline of SOLEIL to perform high-speed XCT in the Ultra-fast Tomography Paris-Edinburgh cell (UToPEc). The UToPEc is a panoramic (i.e. $165^{\circ}$ angular aperture) press optimised for fast tomography that can access $10 \mathrm{GPa}$ and $2000 \mathrm{~K}$. Compact, it is installed on a high-speed rotation stage (up to $360 \%$ s), and allows the acquisition of a full CT-image with micron spatial resolution within a second. This marks a major technical breakthrough for time-lapse XCT and the real-time visualization of evolving dynamic systems. In this paper, we provide a practical step-by-step guide from CT images collection, reconstruction to quantitative analysis to account for the constraints imposed by high-pressure and temperature experimentation. The tomographic series allows the tracking of key topological parameters such as phase fractions from 3D volumetric data, but also the evolution of morphological properties (e.g. volume, flatness, dip) of each selected entity. The potential of this 4D tomography is illustrated by percolation experiments of carbonate melts within solid silicates, relevant for magma transfers in the Earth's mantle.
\end{abstract}

Keywords: X-ray absorption microtomography; high pressure - high temperature; melt migration.

\section{Introduction}

$\mathrm{X}$-ray computed tomography (XCT) is established as a powerful non-destructive method to characterize multiple properties in three dimensions (Maire \& Withers, 2014). Recently, this technique has been adapted to high-pressure (HP) research (Guignot et al., 2020) either in triaxial rig 
(Renard et al., 2016), large volume presses (LVP) such as Drickamer (Wang et al., 2005) and ParisEdinburgh modules (Philippe et al., 2016), or diamond anvil cells for ultra-high pressure conditions (Liu et al., 2008; Mao et al., 2019). Major constraints for high-pressure experiments come from the sample confined environment (i.e. pressure medium and anvils) and the equipment size, which makes the sample not directly accessible and prevents short sample/detector distance required for highresolution imaging. The first LVP used for tomography measurements was a modified Drickamer cell fitted in a 250-ton hydraulic press at GSECARS (Wang et al., 2005). Since, numerous improvements have been made, including the use of toroidal opposed anvils, and attenuation-XCT are routinely obtained up to $8 \mathrm{GPa}$ and $2000 \mathrm{~K}$ in a number of scientific applications (Yu et al., 2016). To enhance equipment compactness and portability at synchrotron sources, a tomography module was also developed for Paris-Edinburgh presses (Philippe et al., 2016). The RoToPEc (Rotating Tomography Paris-Edinburgh cell) allows tomographic studies under high pressure and temperature, up to $10 \mathrm{GPa}$ and $2000 \mathrm{~K}$ with conventional tungsten carbide anvils, either in absorption or diffraction scattering mode (Álvarez-Murga et al., 2017; Boulard et al., 2020). Both systems rely on rotating anvils supported by thrust bearings inside the load frame, and the use of X-ray transparent containment rings and cell assemblies so that the sample could be imaged over $360^{\circ}$. Despite the development of these techniques, the range of application is limited by the rotation speed of the anvils. Indeed, $\mu \mathrm{CT}$ tomographies are typically recorded in twenty minutes or more, making tomographic reconstruction impossible if the sample undergoes plastic deformation or either structural and chemical changes during the acquisition of the projection images. Studies of dynamic processes with second to minute characteristic times are thus impossible.

To overcome this limitation, a Paris-Edinburgh press optimized for fast tomography has been developed, i.e. the UToPEc for Ultra-fast Tomography Paris Edinburgh cell (Boulard et al., 2018). Based on a modified two-column press (Klotz et al., 2004), the UToPEc is compact ( $\varnothing 170 \mathrm{~mm}, 20$ $\mathrm{kg}$ ) and can be installed on a high speed rotation stage for continuous image acquisition. It also offers a large $165^{\circ}$ angular opening, and hence limited blind angles that can be tolerated or corrected for by reconstruction algorithms (Turpin et al., 2020). Pressure and temperature up to $10 \mathrm{GPa}$ and $2000 \mathrm{~K}$ can be targeted with a micrometric spatial resolution for $3 \mathrm{D}$ volumes recorded in less than $1 \mathrm{~s}$ at full rotation speed.

In this paper, we present the specificity of high-pressure tomography as a practical step-by-step handbook from experimental set-up to possible results by detailing acquisition, reconstruction, segmentation, and quantification procedures. The interest of such temporal resolution will be exposed through the example of carbonate-rich melts migration in the Earth's upper mantle. This case study will illustrate fluid percolation monitoring through characterization of flow dynamic and geometry as well as morphological tracking of entities.

\section{Experimental set up}




\subsection{X-ray tomography set-up at PSICHE Beamline}

$\mu$-XCT experiments were conducted on the high pressure beamline PSICHE at synchrotron SOLEIL (King et al., 2019; Figure 1). A high-flux parallel X-ray beam with a mean energy around $45 \mathrm{keV}$ is produced by filtering the polychromatic source ("pink" beam illumination), and provides a $3 \mathrm{~mm} \times 1.5$ $\mathrm{mm}$ field of view and fast exposure time. Transmitted images are converted into visible light and recorded by a $100 \mu \mathrm{m}$ thick $\mathrm{LuAg}$ scintillator screen, coupled by a microscope objective lens to a PCO Dimax CMOS high-speed camera (pco.dimax HS4. PCO AG, Germany) capable of recording 2000 images/s. High temperature and pressure conditions were achieved using the UToPEc press. The small size of the press allows the sample to detector distance to be reduced and hence achieve a better spatial resolution by reducing blurring due to beam divergence. Using a $7.5 \mathrm{x}$ optical magnification results in an effective pixel size of $1.47 \mu \mathrm{m}$, with $4-5$ micron true resolution in the reconstruction (King et al., 2019).

The UToPEc is mounted on $\mathrm{x}-\mathrm{y}-\mathrm{z}$ translational and rotational stages using rotary couplings that allows a continuous rotation of the press up to $360 \%$ shile maintaining the electrical current and hydraulic cooling supplies (Guignot et al., 2020). To date, the hydraulic oil is not yet connected via rotary joints. Pressure must be adjusted prior to tomographies acquisition. Then, a valve seals the system while the oil pump is disconnected. The set-up is also compatible with X-ray diffraction which was used for the measurements of pressure using an hBN-based calibration (Le Godec et al., 2000).

\subsection{Time-resolved XCT experiments}

An experiment was designed to study the percolation of a liquid carbonate phase through an aggregate of solid silicate grains. Starting materials consisted of a $0.4-0.6 \mathrm{~mm}$ thick layer of barium carbonate $\left(\mathrm{BaCO}_{3}\right.$ nano-powder from Alfa Aesar) enclosed in between layer of polycrystalline olivine $\mathrm{Mg}_{0.9} \mathrm{Fe}_{0.1} \mathrm{Si}_{2} \mathrm{O}_{4}$ powder (Figure 1). The micron-sized $(\varnothing<100 \mu \mathrm{m}$ ) olivine grains were sorted from a natural San Carlos peridotite specimen, and included sporadic iron oxides and pyroxenes impurities. The choice of $\mathrm{BaCO}_{3}$ heavy carbonate as the upcoming liquid was made to enhance its $\mathrm{X}$-ray absorption contrast with the olivine solid matrix. Tungsten carbide spheres were also embedded within the olivine powder as positional reference markers (their necessity will be further explained in subsection 3.1). These "sandwich" samples were loaded in a classical PE assembly (Perrillat, 2008) with hBN capsule, graphite furnace, 10mm boron-epoxy gasket, and a PEEK containment ring (Figure 1).

Samples were first pressurized to $2 \mathrm{GPa}$. This cold compression stage led to a strong reduction of the olivine powder initial porosity to achieve a value of 5-10\%. Temperature was then increased by steps above the melting point of $\mathrm{BaCO}_{3}$ (i.e. $\mathrm{T}>800^{\circ} \mathrm{C}$ ) for $\mathrm{CT}$-imaging of liquid migration. The entire process under extreme conditions lasts over one hour; after which samples were quenched and 
prepared for SEM observations. Table 1 summarizes P-T conditions and XCT acquisition characteristics for studied samples.

The real-time monitoring of $\mathrm{BaCO}_{3}$ liquid migration was limited over time by the capacity of the onboard memory of the CMOS camera and the duration of data transfer to the storage network. For the field of view needed in this experiment, i.e. the whole gap between the anvils, a maximum of approximately 15000 projections $(1500 * 1500$ pixels) could be recorded, corresponding to about 15 CT images. The data transfer of the projections corresponding to a single CT image to the storage network took approximately $1 \mathrm{~min}$. In order to capture the motion of carbonate liquid, with second to minute resolutions, we defined a sequence of 12-15 CT scans of 1s duration with a $15 \mathrm{~s}$ interval between each tomogram. Data were downloaded from the camera after each sequence (transfer took about 10-15 min). Dark and flat field images were recorded at the beginning and end of each sequence as spatial and temporal inhomogeneity of the incident beam, scintillator, and CMOS response are negligible in such a short period $(<4 \mathrm{~min})$. Three such cycles were performed for each sample (see Table 1).

Figure 1 UToPEc setup used in parallel pink beam XCT configuration and PE assembly with "sandwich" configuration starting sample.

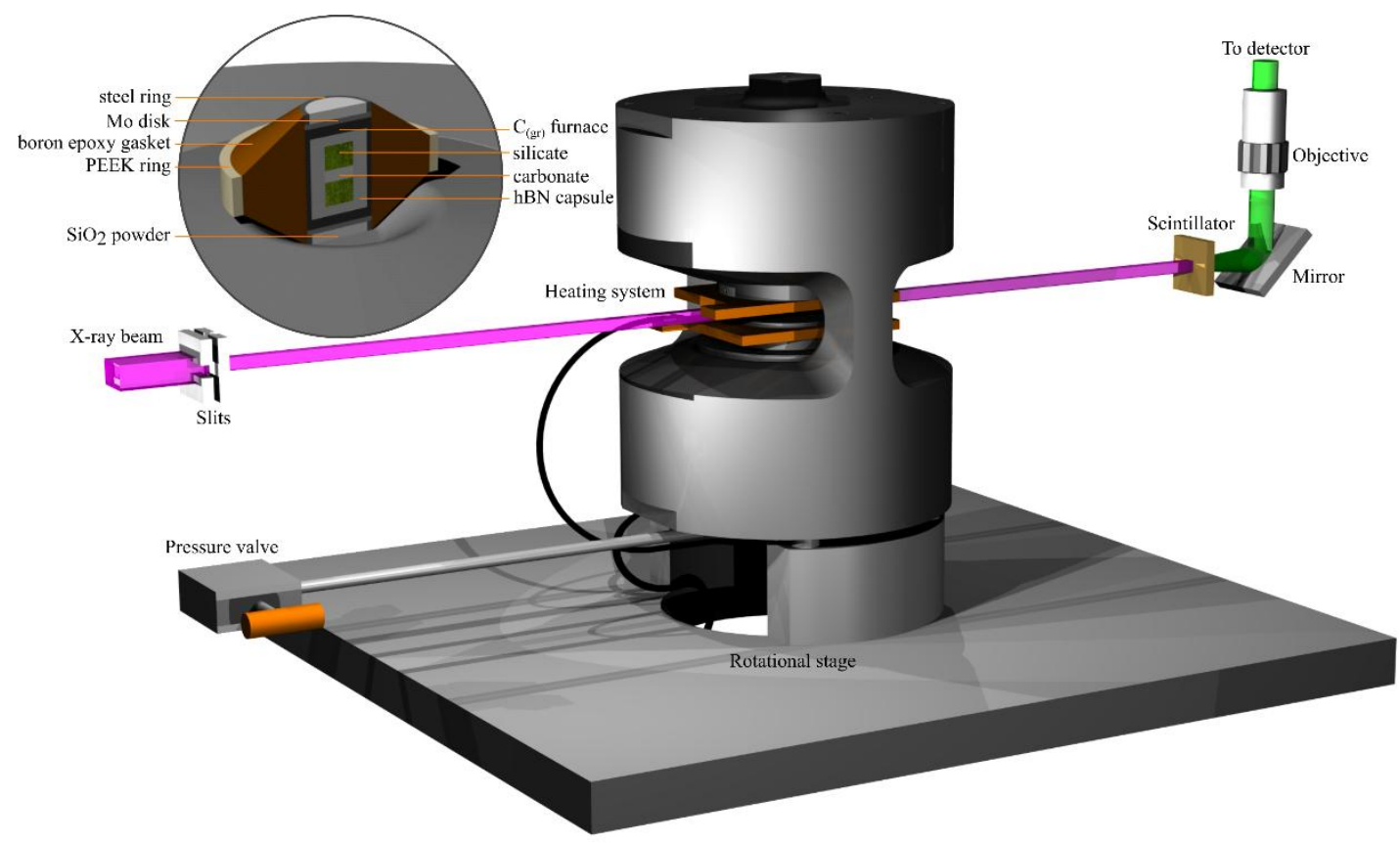

Table 1 Summary of experimental conditions and data acquisition. LT abbreviation is for latency time corresponding to the delay time in between cycles. Duration corresponds to the total amount time above melting point. Cycle of 12 and 15 tomographies last over $\sim 3$ min and $\sim 4$ min, respectively. Pressure was calculated from h-BN cell parameters and the equation of state of Le Godec et al. (2000). Temperature was estimated by power temperature relation curve determined in a previous experiment using a thermocouple. 


\begin{tabular}{|c|c|c|c|c|c|c|c|c|c|c|c|}
\hline \multirow{2}{*}{$\begin{array}{l}\text { Sample } \\
\text { name }\end{array}$} & \multirow{2}{*}{$\begin{array}{l}P_{\text {initial }} \\
(\mathrm{GPa})\end{array}$} & \multicolumn{2}{|c|}{ Cycle 1} & \multirow{2}{*}{$\begin{array}{l}\text { LT } \\
(\min )\end{array}$} & \multicolumn{2}{|c|}{ Cycle 2} & \multirow{2}{*}{$\begin{array}{l}\mathrm{LT} \\
(\min )\end{array}$} & \multicolumn{2}{|c|}{ Cycle 3} & \multirow{2}{*}{$\begin{array}{l}\text { Duration } \\
\text { (min) }\end{array}$} & \multirow{2}{*}{$\begin{array}{l}\mathrm{P}_{\text {final }} \\
(\mathrm{GPa})\end{array}$} \\
\hline & & $\mathrm{T}\left({ }^{\circ} \mathrm{C}\right)$ & Tomo\# & & $\mathrm{T}\left({ }^{\circ} \mathrm{C}\right)$ & Tomo\# & & $\mathrm{T}\left({ }^{\circ} \mathrm{C}\right)$ & Tomo\# & & \\
\hline BaCarb1 & 2.0 & 890 & 12 & +12 & 890 & 12 & +30 & 890 & 12 & 62 & 0.45 \\
\hline BaCarb3 & 1.6 & 830 & 15 & +11 & 955 & 15 & +15 & 1040 & 15 & 42 & 0.50 \\
\hline
\end{tabular}

\section{Analysis methods}

\subsection{CT image reconstruction and pre-treatment}

Each tomogram consisted of 900 projections recorded over $180^{\circ}$ rotation in $1.035 \mathrm{~s}$. Volume reconstruction was performed via standard filtered backprojection using PyHST2 (Mirone et al., 2014), and applying flat field correction and Paganin phase retrieval (Paganin et al., 2002). The presence of $15^{\circ}$ missing angles did not produced noticeable artefacts affecting the volume quality as already observed by Urakawa et al. (2010) and Boulard et al. (2018).

After reconstruction, data correspond to a stack of XY-slices in 32bits-float data format. These data were converted into 8bits-integer format to reduce memory requirements and facilitate their analysis. This conversion was performed with ImageJ using the automatically optimisation of brightness and contrast based on image histogram. Display range values were determined on tomography slices within the olivine matrix to enhance interstitial carbonate visibility and were kept the same for all tomographies. Small amount of pixels was allowed to become saturated ( 0 or 255$)$ as visible later on the resulting 8bits histogram used for thresholding. Representative subvolumes were then extracted to reduce calculation time during segmentation and post-processing with dimensions of $1275 \times 1325 \times 435$ voxels (i.e. $\approx 1875 \times 1948 \times 639 \mu \mathrm{m}$ ) for BaCarb1 and 1300x1250x402 voxels (i.e. $\approx 1911 \times 1838 \times 591$ $\mu \mathrm{m})$ for BaCarb3 (see Figure 2 for an illustration).

Figure 2 Tomographies cross-sections with studied sub-volume representation. Figured crosssections are from the last CT-images of cycle 3 for both samples BaCarb1 and BaCarb3 (cf Table 1 for more details). 


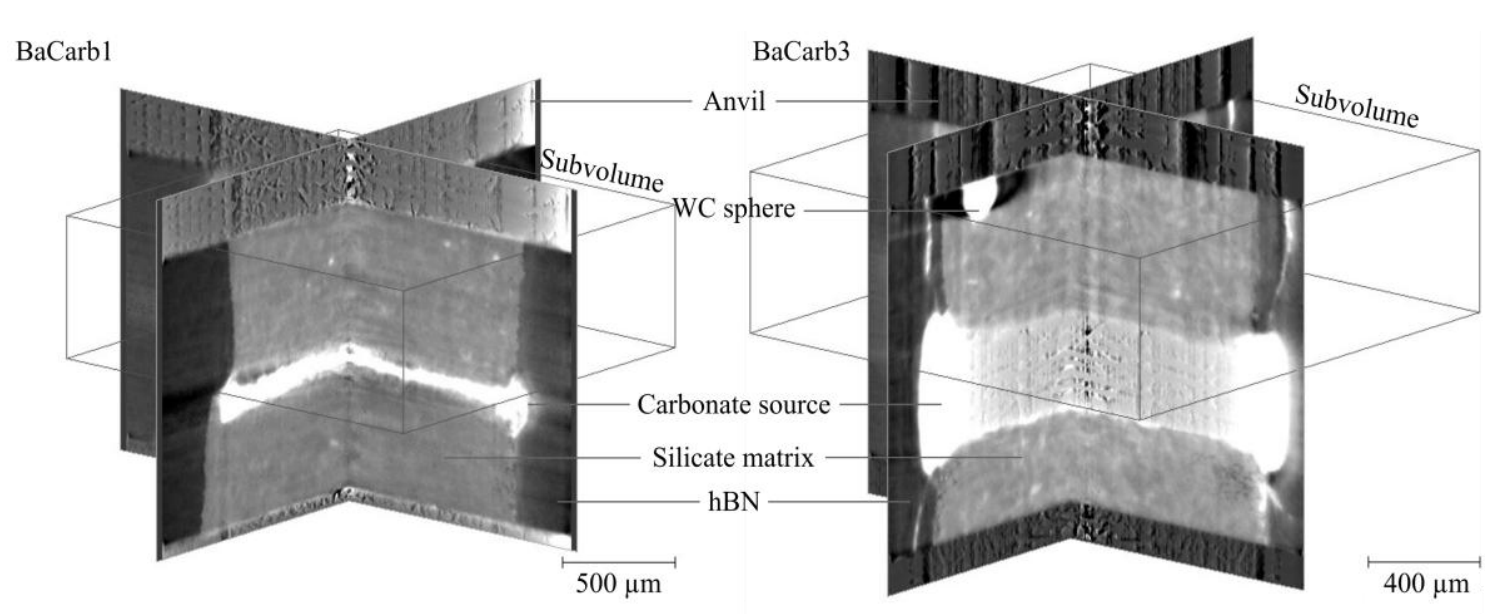

In order to make quantitative comparisons between successive tomographies, the 3D datasets must be spatially aligned. Inherent issues from the high-pressure experiments must be addressed. (i) First, at high temperature, despite the PEEK containment ring, the experimental assembly flows and induces a translation of the sample along the vertical-axis as well as a reduction of the gap between anvils. We used WC sphere markers embedded in the olivine sample to correct this absolute motion. These benchmarks also confirm that plastic deformation did not occur within the polycrystalline aggregate under HP-HT since distances between markers remained constant. (ii) Moreover, due to the continuous rotation of the press and the delay between successive CT-scans, an angular jitter is observed between tomographies within the same acquisition cycle and between different cycles. This misalignment results in different absolute rotation stage position for each dataset that can reach $20^{\circ}$. To correct this offset, 3D volumes are rotated to one another using a Python script that involves the barycentre (i.e. center of mass of entity associated voxels) of the markers. After these corrections, subvolumes can be overlapped and are thus suitable for subsequent segmentation and quantification.

\subsection{CT image segmentation}

After conversion to 8bit-integer format, each voxel in the subvolume is characterized by a grey level value, from 0 to 255 , that reflects the local X-ray attenuation coefficient. Here highly absorbent elements, such as $\mathrm{BaCO}_{3}$, appear brighter on $\mathrm{CT}$ slices relative to silicate grains (Figure 3b). The segmentation enables the isolation of voxels with particular intensity values, and their assignment to a phase, either carbonate or olivine silicate. This segmentation step was performed with the Thermo Scientific Avizo (C) software, using a user-controlled hysteresis thresholding. It consists of a dual thresholding operation, where the first threshold (upper value) determines high-confidence areas - any pixel value above it will be undeniably associated with carbonate - while the second threshold (lower value) consists of an extension of those areas - areas above this threshold are considered to be carbonate if they are connected to high confidence areas. Both threshold values were determined from the grey scale histogram (Figure 3c), and were constant for each tomography sequence. 
The choice of these threshold values is the main source of uncertainty on estimates of carbonate vs silicate volumes, since the projection grey-level can slightly fluctuate between CT-images. We assess this uncertainty by running multiple segmentations with similar first threshold value but varying the second threshold by \pm 2 grey levels. This range corresponds to the possible values for the extension of the high-confidence limit as above +2 some carbonate information is not taken into account and below -2 segmentation induced noise and tomographic default enhancement. In subsection 4.1 those uncertainties will be represented as envelopes and will be use to select CT-scan to be compared.

After segmentation, slices are binary images where 0 corresponds to the silicate matrix and 1 to carbonate elements. Segmented entities not related to the $\mathrm{BaCO}_{3}$ liquid migration, like WC-markers or the carbonate source layer, that are far bigger than target melt pockets are removed using a filter based on a volume limit. For each carbonate entity in the subvolume, identified as labelled-blobs, we computed position properties and shape characteristics (volume, Feret distances (length and thickness), flatness and orientation) using Avizo@ predefined functions (BaryCenterX, BaryCenterY, BaryCenterZ, Volume3d, Length3d, LengthOrientTheta, LengthOrientPhi, Width3d, WidthOrientTheta, WidthOrientPhi).

Using positional barycentre information, cylindrical regions of interest (ROI) within subvolumes were defined to avoid edge defects (e.g. liquid flow along the edges of the capsule). All entities whose barycentre is included in the cylinder will be kept in its entirety, so that blobs located at the boundary of ROI are not cropped. The ROI characteristics for BaCarb1 and BaCarb3 are $294 \mu \mathrm{m}$ height - 588 $\mu \mathrm{m}$ radius and $367.5 \mu \mathrm{m}$ height and $441 \mu \mathrm{m}$ radius respectively (Figure $3 \mathrm{e}$ ).

Figure 3 Visualization of the X-ray CT data. (a) View of the BaCarb1 subvolume. (b) Representative tomography slice of the olivine polycrystals impregnated by $\mathrm{BaCO}_{3}$ (bright area). (c) Histogram of grey scale values of the 1100x1100x325 $\mu$ m subvolume within the polycrystalline matrix (see squared area in (b)). Representative grayscale values of "olivine" and "carbonate" are figured. (d) Segmented carbonate blobs after hysteresis thresholding. Position and shape properties of each entity are computed. (e) Only coloured entities are studied. 


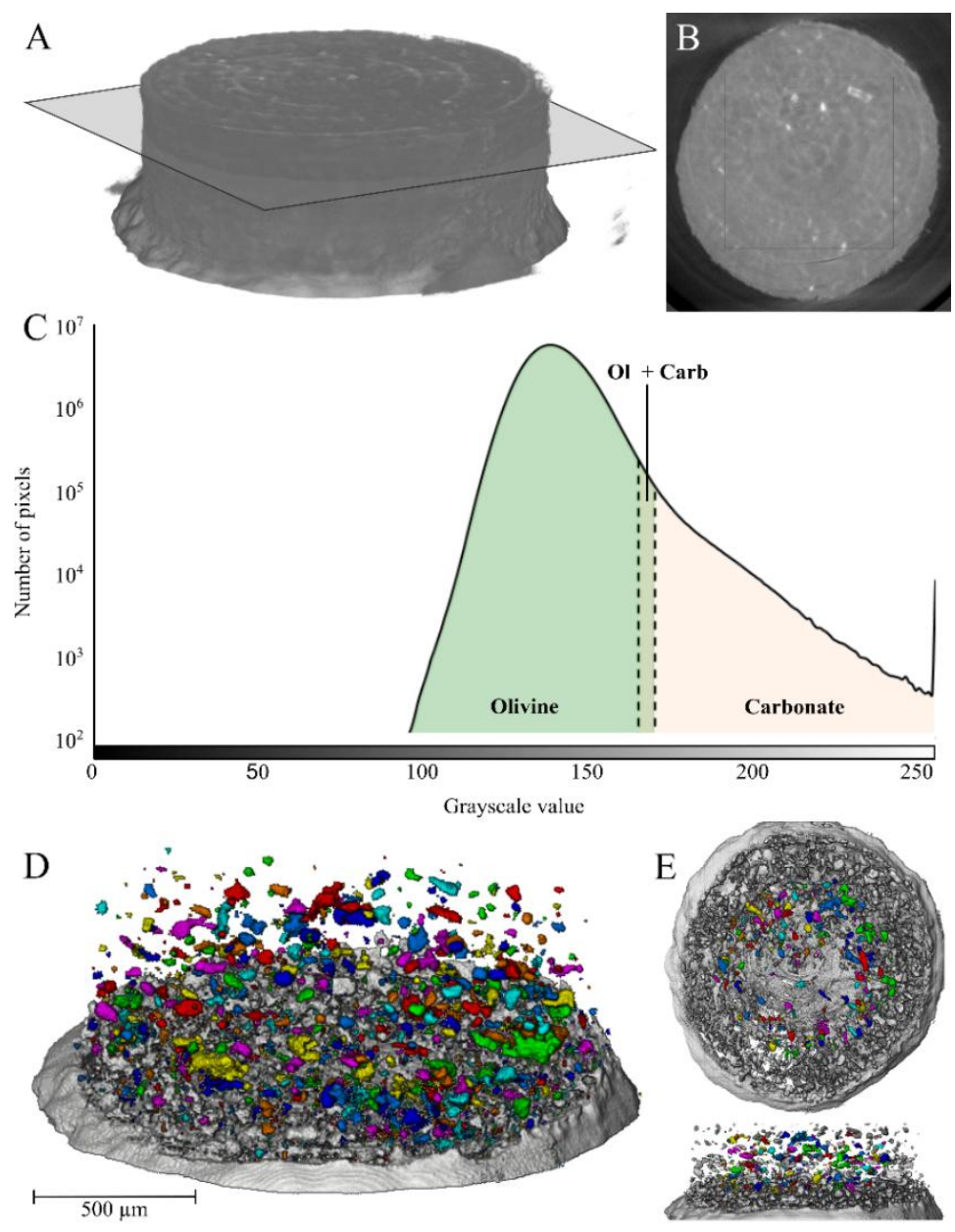

\subsection{Flow quantification}

The time resolution of $16 \mathrm{~s}$ between successive tomographies enables a real-time monitoring of porosity impregnation by $\mathrm{BaCO}_{3}$ liquid, which starts soon after carbonate melting. A simple way to quantify this flow is to track the migration front, i.e. the maximal height where fluids are detected along the z-axis, for each CT-image. To further estimate the 3D volumetric distribution of liquid over time, the carbonate voxels for each slice were summed along the $z$-axis. The obtained cumulative curve (Figure 4) depicts the contribution of each z-slice on the total amount of liquid. If a linear relation is observed, then the carbonate input is constant regardless of the vertical position in the sample, and the slope provides a volumetric flow rate.

Figure 4 Quantification of flow dynamics, counting every segmented voxel within the cylindrical ROI (dashed line) and studying its cumulative curve for one $\mu \mathrm{CT}$. Both tomography slices illustrates the quantity of counted voxels (considering the $1.47 \mu \mathrm{m}^{3}$ voxel size, 2820 voxels correspond to $\sim 9000$ $\mu \mathrm{m}^{3}$ and 6656 voxels to $\sim 21000 \mu \mathrm{m}^{3}$ ). The left axis displays the absolute volume associated to the voxel count and the right axis represents its comparison to the ROI volume. In this example $1 \%$ of total volume is segmented as carbonate. 


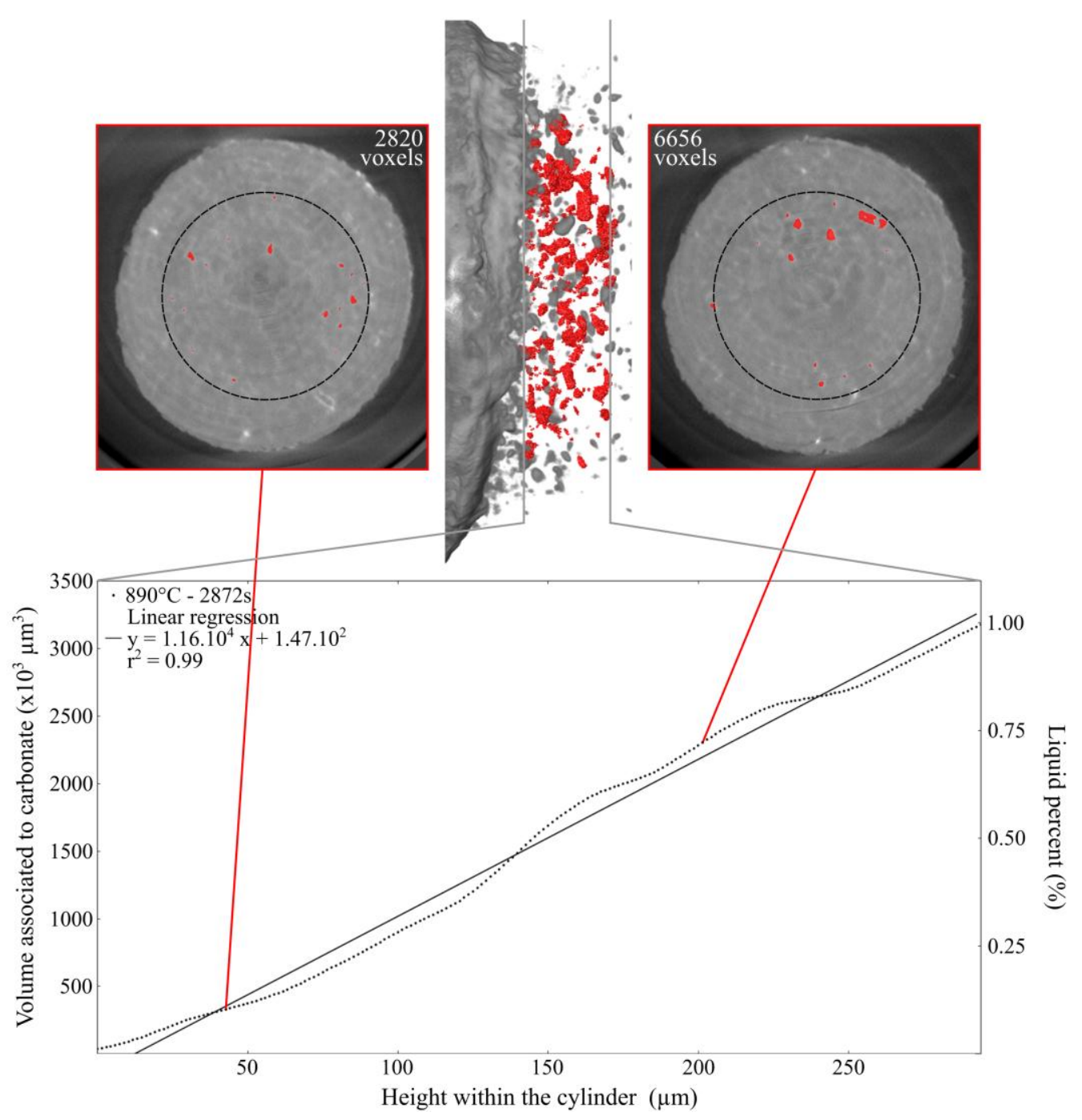

\subsection{Object-based analysis}

To better constrain flow geometrical characteristics, 3D data can be studied regarding each segmented entity. Within cylindrical ROI, the number of carbonate melt pockets varies between 100 and 300 . They were investigated in term of volume, shape and inclination statistics, as well as entity tracking. Upcoming paragraphs and Figure 5 describe briefly the calculation of these parameters.

\subsubsection{Shape analysis}

Blob shape was characterized using Feret minimal and maximal diameter. The Feret diameter is a measure of an object size along a specified direction. It can be defined as the distance between two parallel tangents to the contour of the object. Distances were computed along with a series of orientations, $\Theta$ and $\varphi$ varied from 0 to $180^{\circ}$ and -90 to $90^{\circ}$, respectively, with an interval of $1^{\circ}$. Feret minimal and maximal distances characterize entities' thickness (shortest distance) and length (longest distance), respectively. In term of aspect ratio, entity flatness can be computed from $1-\frac{F_{\min }}{F_{\max }}$, such that 0 corresponds to a sphere and 1 to a plane. 


\subsubsection{Entities inclination}

Orientation statistics were obtained on elongated $\mathrm{BaCO}_{3}$ blobs (aspect ratio above 2:1) by measuring their dip angle relative to the X-Y plane of the subvolume. Inclination statistics are represented by rose diagrams (Figure 10), and reveal the orientation of melt pockets between solid grains.

\subsubsection{Tracking}

The 3D alignment of tomograms (see subsection 3.1) enables particles tracking between successive CT-images. In this way, the morphological evolution of each entity, identified by its barycentre, can be quantified using the above-defined volume, shape and orientation parameters. Nevertheless, depending on the case of study, entities could disappear, split, or merge (either physically or due to data resolution). In consequence, this approach is limited to restricted set of particles of interest. An example, of melt pocket tracking is shown in Figure 12 and discussed in subsection 4.3.

Figure 5 Example of object based analysis. Upper left figure represents a carbonate entity from BaCarb3 sample. Its length can be visualised along the white arrows, its thickness along grey ones. Its dip is measured in the orthogonal system defined by the subvolume - Lower left figures illustrate its morphological evolution over time as tracked by time-lapsed CT-scans - On the right, graphs show the evolution of studied geometrics parameters along the three different temperature cycles. The increase in length and thickness of the particle depicts the growing volume of melt over time, while the dip angle and flatness parameters of the particle remain more or less constant. 

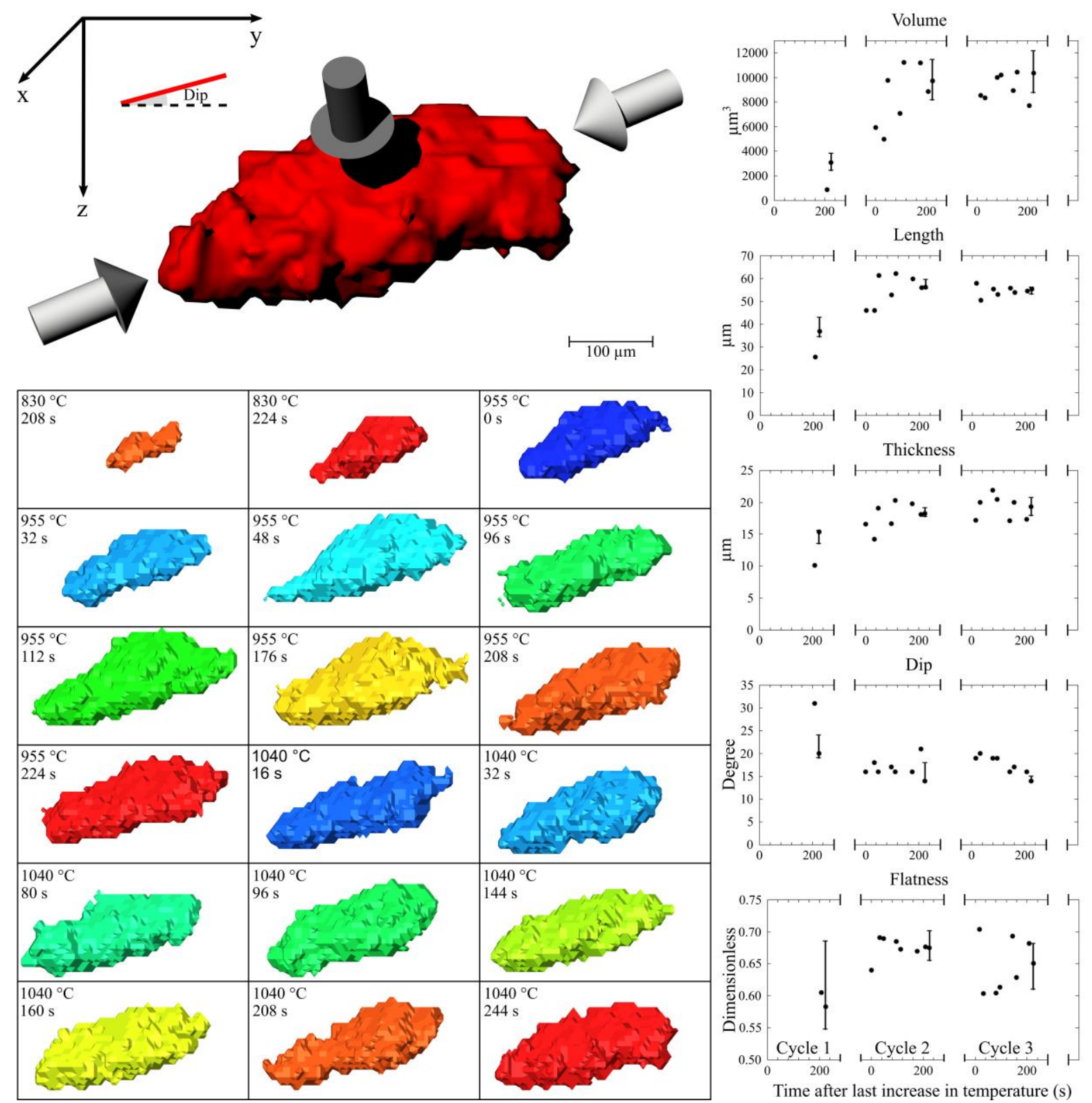

\section{Results \& Discussion}

\subsection{Impregnation rate and dynamic}

In both experiments BaCarb1 \& BaCarb3, the liquid impregnation started as soon as the melting temperature was crossed, as evidenced by the appearance of melt pockets away from the initial carbonate layer already on the first tomography. The further CT-images allow tracking the progression of the migration front with a 16s resolution. Figure 6 shows eight reconstructions recorded for sample BaCarb1 in the first 176s of experiment and the distribution of carbonate voxels along the z-axis (where 0 represents the position of the initial $\mathrm{BaCO}_{3}$ layer) for each CTreconstruction. The progression of the porosity infill by carbonate is clear between the $48 \mathrm{~s}, 80 \mathrm{~s}, 96 \mathrm{~s}$ and $112 \mathrm{~s}$ CT images to reach the top end of ROI. This way, we can estimate that initial impregnation 
took place over a distance of at least $115 \mu \mathrm{m}$ between CT scans recorded at $48 \mathrm{~s}$ and $120 \mathrm{~s}$ that translates into an average vertical rate of $5.35 \mathrm{~mm} / \mathrm{h}$.

In sample BaCarb3, tracking of this impregnation front was made difficult by the presence of sporadic oxide impurities in the olivine powder that biases the identification of newly-formed small melt pockets. However, on the last CT-image recorded after $224 \mathrm{~s}$, the $\mathrm{BaCO}_{3}$ melt is well dispersed and reached the top end of the ROI. As the sample maximal observable height was $368 \mu \mathrm{m}$, a mean impregnation rate of $5.91 \mathrm{~mm} / \mathrm{h}$ can be estimated.

These impregnation rates can be compared with SEM observations on the quenched samples. Indeed, considering that experiments lasted about one hour over melting temperature (62 min for BaCarb1 and 42 min for $\mathrm{BaCarb3}$ ) and that $\mathrm{BaCO}_{3}$ liquid is observed over the entire 0.9-1mm thick olivine matrix on SEM images, leads to an average rate of $1 \mathrm{~mm} / \mathrm{h}$ for BaCarb1 and $1.35 \mathrm{~mm} / \mathrm{h}$ for BaCarb3. Not surprisingly, this estimate is significantly lower than the in situ measurements, highlighting, the need for in situ analyses.

Figure 6 Visualisation of the carbonate melt impregnation front in sample BaCarb1. Vertical projections of cylindrical ROI are represented for eight tomographies over time. The carbonate source is located at the image bottom. With time, melt blobs are more numerous and located further from the initial layer. The plot on the right shows the distribution (arbitrary unit) of voxels segmented as carbonate along the ROI. Once a porosity is filled the elongation, flatness and dip of the associated pocket remain relatively constant over time, as its volume grows.

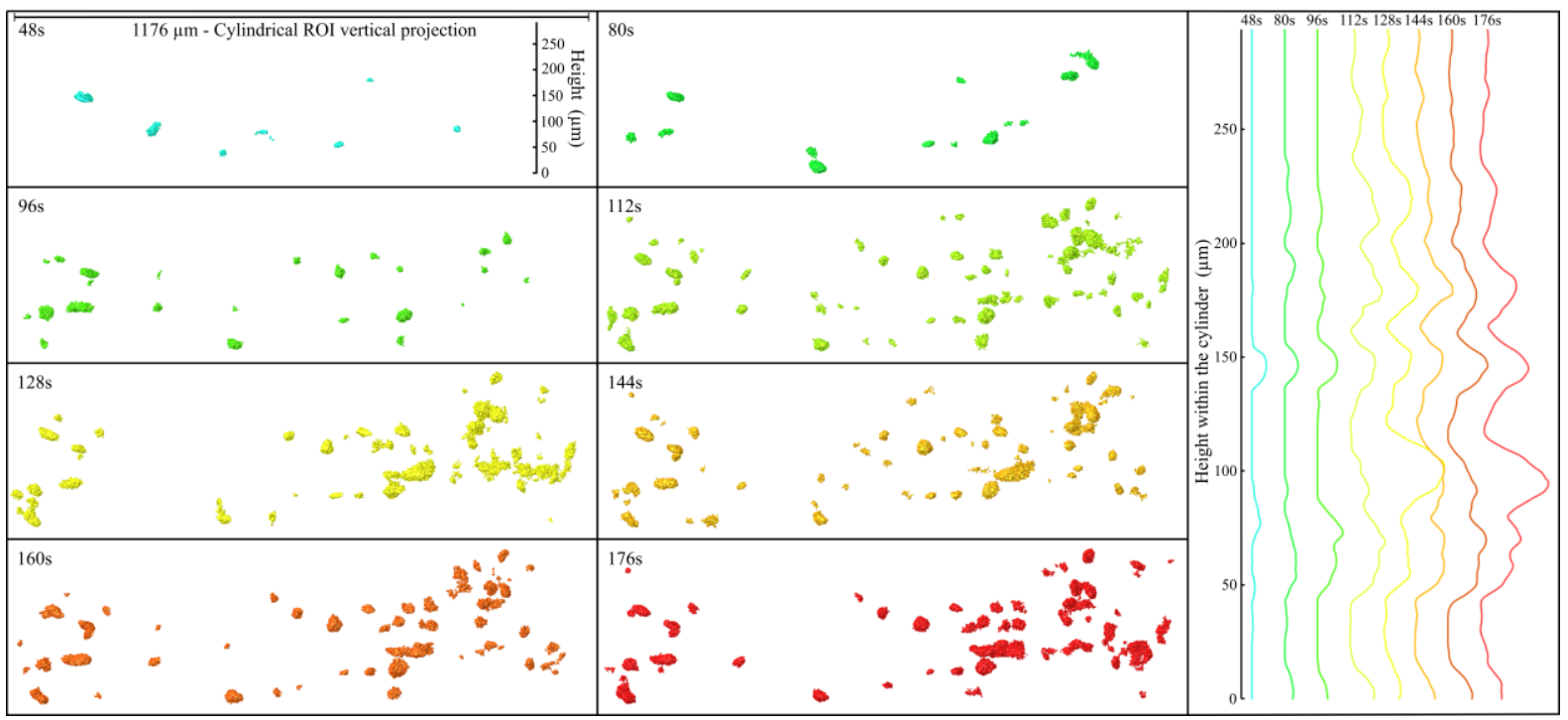

The evolution of the volumetric flow rate as a function of time and temperature is quantified from the distribution of carbonate blobs on successive reconstructions. All cumulative carbonate curves (see subsection 3.3) obtained for each CT-image of both samples show a linear trend ( $\mathrm{r}^{2}$ for cycle 2 and 3 are $>0.98$ for BaCarb1 and $>0.93$ for BaCarb3) meaning that the carbonate input is constant 
regardless of the vertical position in the sample (Figure 7). Nevertheless, the different slopes between each reconstruction imply different carbonate contents.

Figure 7 Cumulative curves of carbonate voxels measured for each CT-image of successive cycle \#1 (in orange), \#2 (in blue) and \#3 (in green) for both samples BaCarb1 and BaCarb3. In one cycle curve colours go from bright to dark as times increases. Uncertainties are represented by an envelope for one tomography (in black) for each cycle.
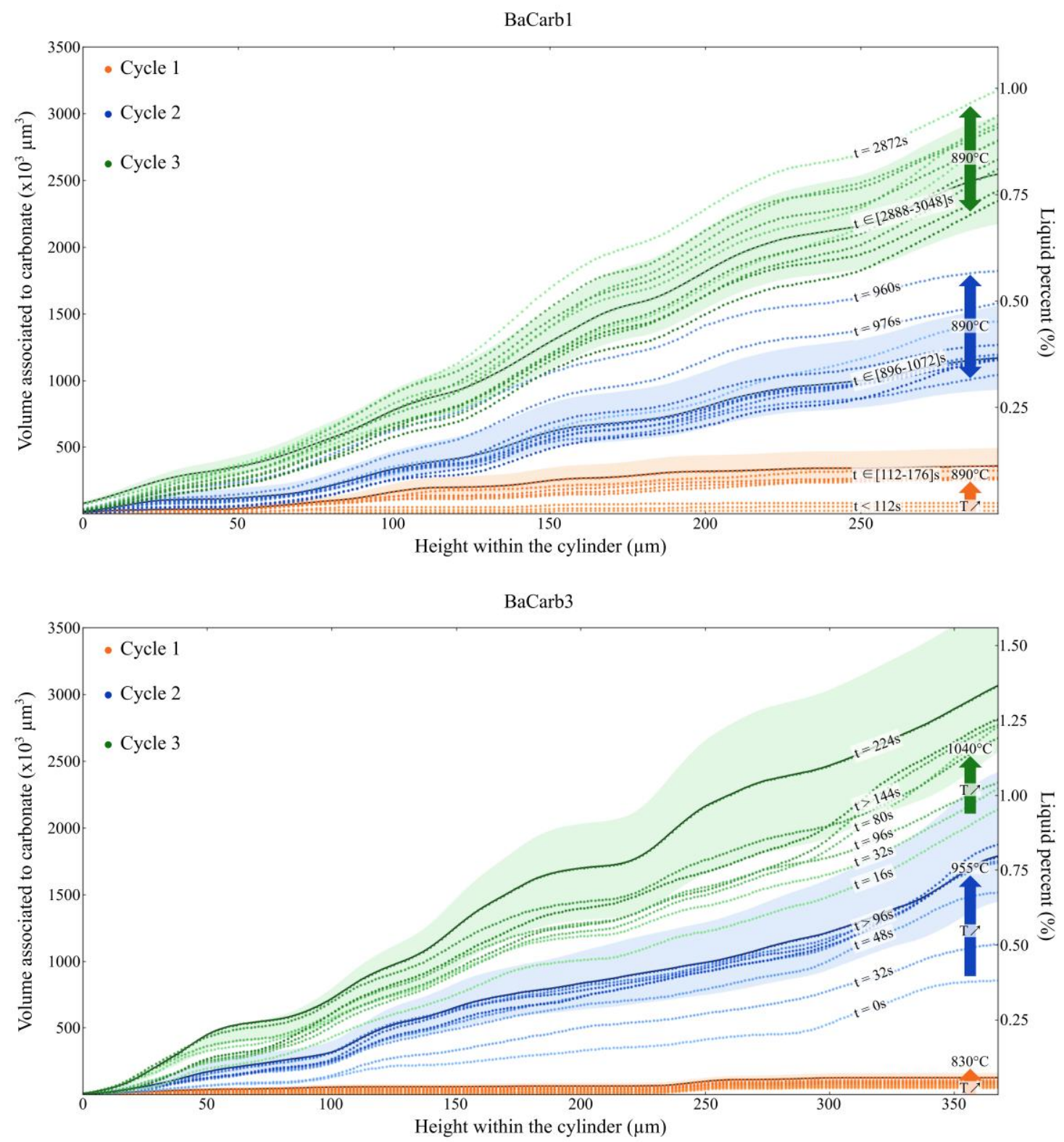

A CT-image can be modelled as a pile of X-Y slices crossed by a uniaxial vertical flow of carbonate voxels. The volumetric flow rate $\left(\mathrm{Q}_{\mathrm{v}}\right)$, i.e. the volume of $\mathrm{BaCO}_{3}$ melt which passes per unit time through a defined slice, is calculated from mass balances between successive CT-images according to

$$
Q_{v}=\frac{1}{d t}\left(\left(S_{t+d t}-S_{t}\right) d l+\left(V_{t+d t}-V_{t}\right)\right)
$$


Where dt is the time interval between CT images, $\left(S_{t+d t}-S_{t}\right) d l$ the cumulated carbonate volume within the slice (following values were obtained on ROI bases), and $\left(V_{t+d t}-V_{t}\right)$ the volume of carbonate that passed through it.

BaCarb1 images depict the evolution of flow rate as a function of time as the temperature was constant at $890^{\circ} \mathrm{C}$ during all the experiment. Flow rates of $4026_{-1378}^{+1936}$ (where subscript and exponent values correspond to the asymmetric errors), $1130_{-358}^{+478}$ and $705_{-200}^{+227} \mu \mathrm{m}^{3} / \mathrm{s}$ were calculated between the $96 \mathrm{~s}-176 \mathrm{~s}, 176 \mathrm{~s}-928 \mathrm{~s}$, and $928 \mathrm{~s}-2904 \mathrm{~s}$ CT-images, respectively. This decrease of flow rates (Figure 8) shows that the melt impregnation became less effective with time. Conversely, in BaCarb3, temperature was increased by steps between each CT-imaging sequence. Each temperature step was associated with a boost in carbonate flow as evidenced by a quick slope increase of first cumulative curve of each series (Figure 7). Flow rates were thus calculated by difference between the first and last image of a sequence, giving flow rates of $266_{-39}^{+354} \mu \mathrm{m}^{3} / \mathrm{s}$ for cycle 1 at $830^{\circ} \mathrm{C}$, $3731_{-647}^{+5315} \mu \mathrm{m}^{3} / \mathrm{s}$ for cycle 2 at $955^{\circ} \mathrm{C}$ and $5350_{-1954}^{+8369} \mu \mathrm{m}^{3} / \mathrm{s}$ for cycle 3 at $1040^{\circ} \mathrm{C}$. As expected, the flow rates increase with increasing temperature, but not linearly since the porosity is getting filled during cycles.

Figure 8 Volumetric flow rates calculated at cylindrical ROI bottom from mass balance models.
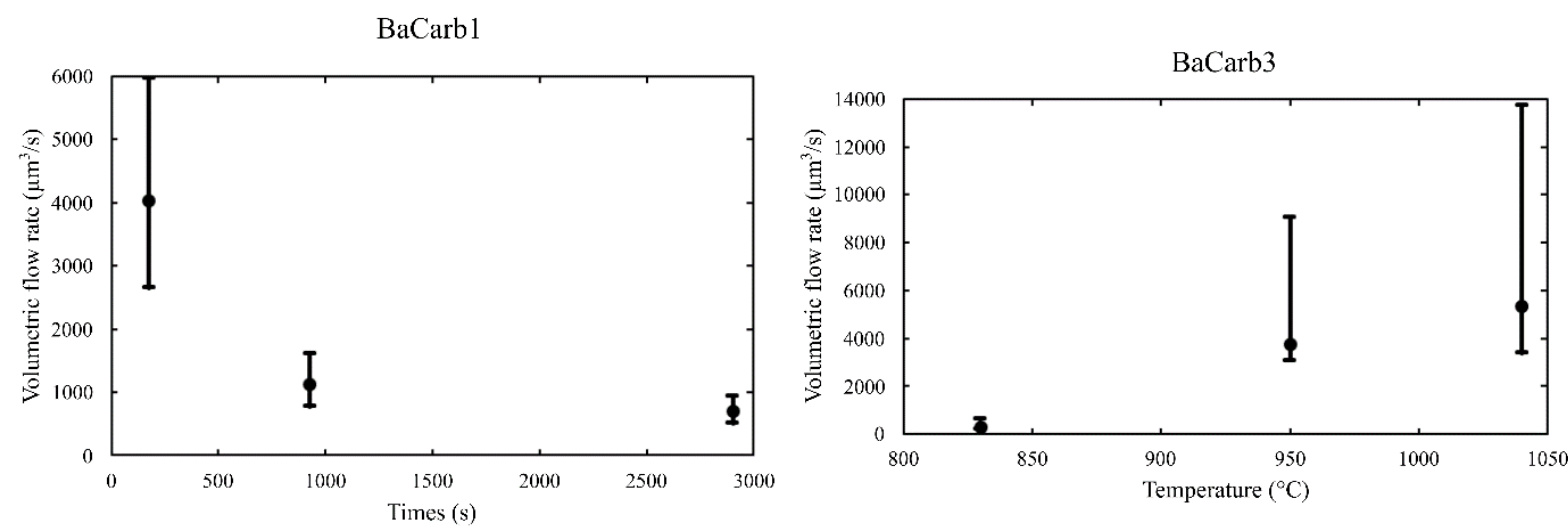

Those observed behaviours of flow rates are characteristic of capillary penetration and fluid transport through porous structures. Indeed, the progression of the wetting front and the decrease of flow rates with time reflect the typical diffusive behaviour of capillary flow (Washburn, 1921). Similarly, the increase in flow rates with temperature highlights the increased diffusivities (i.e. lower viscosities) of carbonate melts at high temperature.

\subsection{Entities morphology}

The evolution of the melt network during impregnation can be addressed by following carbonate entities' morphology. A sorting of $\mathrm{BaCO}_{3}$ blobs as a function of their volumes (Figure 9) reveals a gradual rise in the number of blobs for each size-class and a larger representation of large blobs (> 12 
$500 \mu \mathrm{m}^{3}$ ) over time, for both BaCarb1 \& BaCarb3 runs. This gradual infill is consistent with an increasing saturation of porosity after the initial wetting of olivine grain boundaries by the melt front. The melt flow is accommodated by a homogeneous growth of the melt pockets; as illustrated by the jump in pocket size-class, and the rise in small melt entities $\left(<1250 \mu \mathrm{m}^{3}\right)$ previously under detection limit, between successive CT-images.

Figure 9 Repartition of carbonate entities in volume categories (as coloured labelled) as a function of melt content increase during experiment.
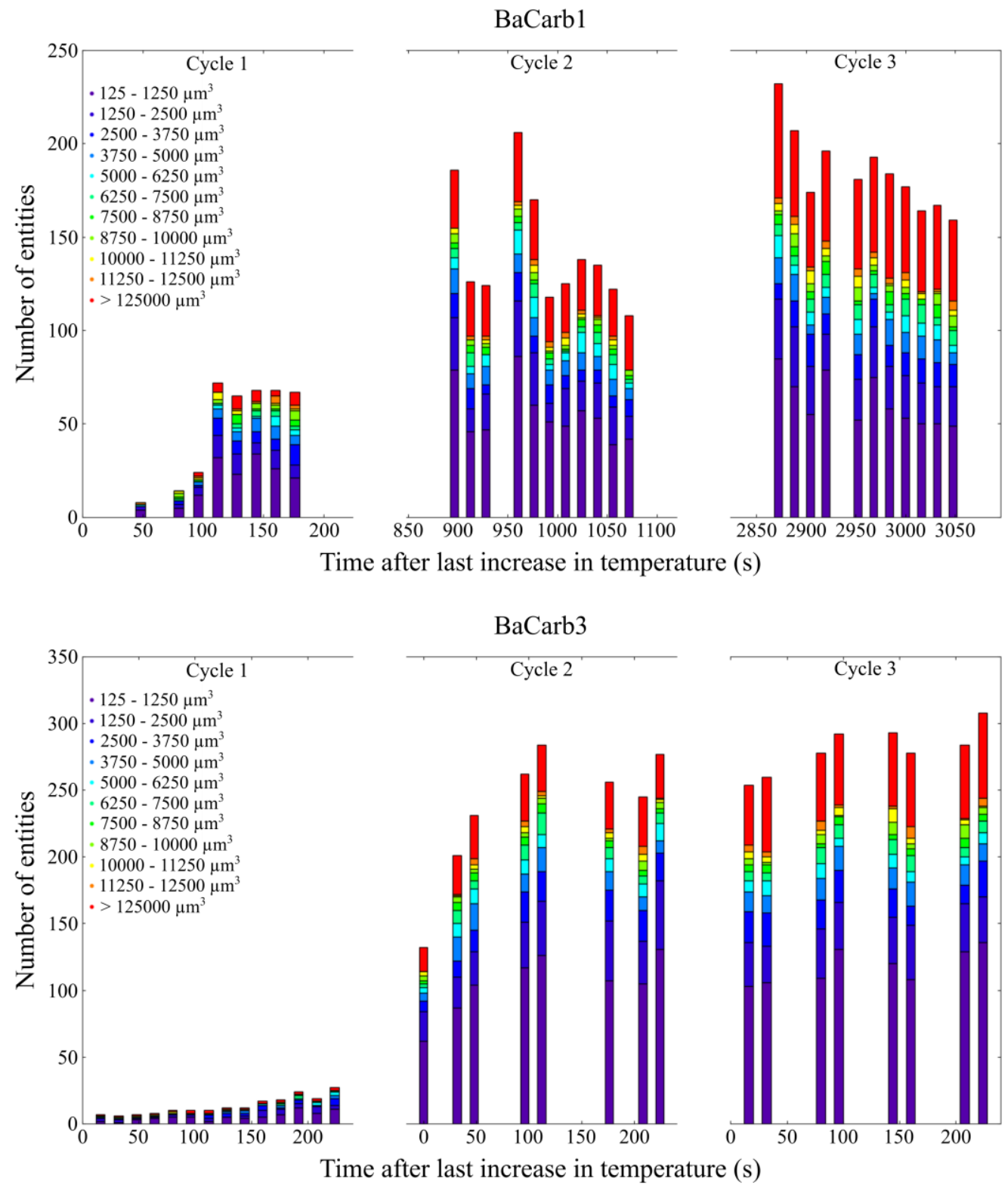

Analysis of the Feret distances and shape ratio (i.e. flatness) lead to similar conclusions. The increase in Feret distances with time reflects the homogeneous growth of melt entities, and their aspect ratio remain constant with a Gaussian repartition centred on 0.5 (i.e. in average the thickness is twice shorter than the length of blobs, with extrema ratio of 1:5 and 4:5) independently of the pocket size. 
The orientation of entities estimated from the dip angle relative to the $\mathrm{X}-\mathrm{Y}$ plane do not show significant variations from the first to the last tomography, with preferred distribution at angles less than $50^{\circ}$ as shown on rose diagrams (Figure 10). These morphological parameters are in agreement with the gradual saturation of the porosity network by $\mathrm{BaCO}_{3}$ liquid.

Figure 10 Orientation analysis through time. Each rose diagram represents the cumulated evolution of the dip angle relative to the $\mathrm{X}-\mathrm{Y}$ plane for an experiment. 90\% of BaCarb1 and BaCarb3 entities have orientation value respectively under $48^{\circ}$ and $51^{\circ}$.

\section{BaCarb1}

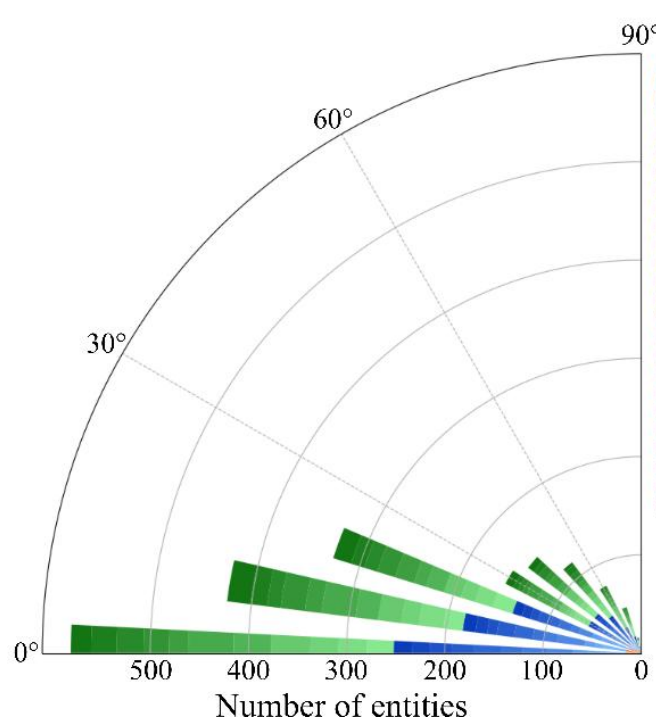

\section{BaCarb3}

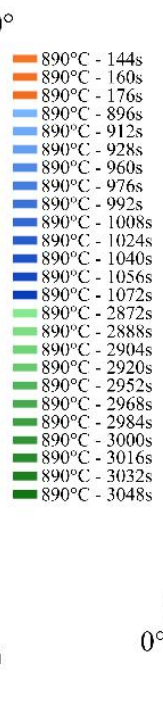

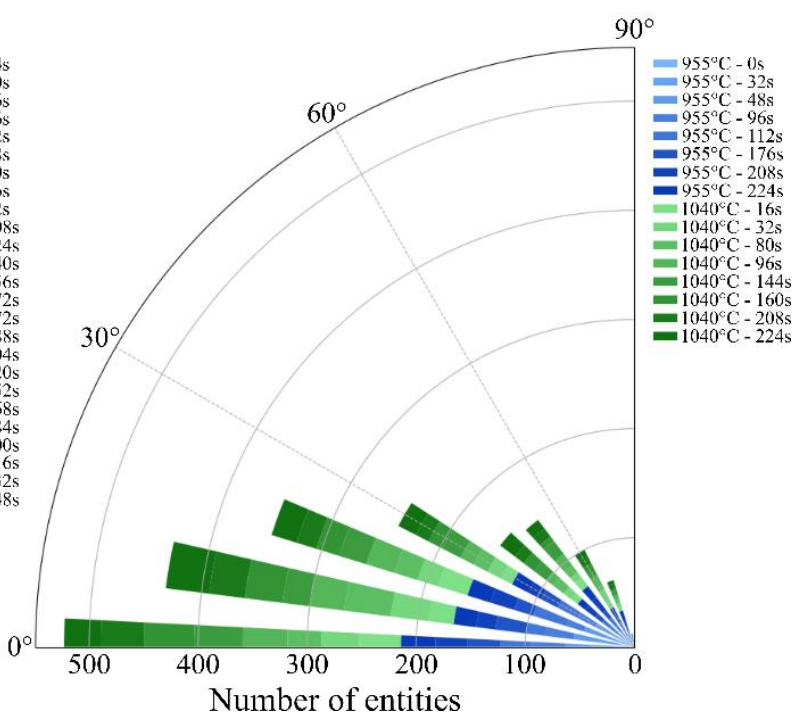

\subsection{Implication for carbonate liquid impregnation process}

Knowledge of the location and transport of magmas in the deep Earth is an important step toward the understanding of geochemical and geodynamical processes at depths. It comes as primary importance for carbon-rich melt as carbonate magmas impact the deep carbon cycle, which remains highly debated. Those carbonate magmas have unique properties, clearly distinct from the widespread silicate liquids, coming from their unpolymerized ionic structure. Due to the weak cohesion of carbonate molecules, these magmas have low viscosities $\left(<10^{-2}\right.$ Pa.s - Dobson et al., 1996; Kono et al., 2014). This high mobility is reinforced by wetting angles lower than $30^{\circ}$ (Hunter \& McKenzie, 1989) and a large buoyancy relative to surrounding mantle rocks (Dobson et al., 1996). Hence, these liquids are expected to form interconnected networks and to be efficiently extracted even at low melt fractions. On a chemical point of view, this large connectivity along grains implies an important exchange surface that makes them highly reactive agents (Green \& Wallace, 1988).

Melt migration is often studied regarding buoyancy forces and external pressure gradients. However capillary forces and associated surface tension effects can also drive magma displacement over geologically relevant distances, particularly for low viscosity fluids (Stevenson, 1986). As revealed by our experiments, capillary forces caused the molten carbonate to infiltrate the polycrystalline olivine. 
Melt migrated from high concentration areas (close to the carbonate source layer) to lower concentration areas, as illustrated in Figure 11. This spatial variation in the melt fraction give rise to a gradient in the effective pressure of the melt, thus providing a thermodynamic driving force for melt migration.

Figure 11 Representative sections of $\mu \mathrm{CT}$ reconstructions over cycles \#1 \#2 \#3 of BaCarb1 showing the progressive infill of the polycrystalline olivine (dark grey areas) by the carbonate melt (in white and light grey). The SEM image of the same section on the quench shows a complete wetting of the porosity with submicron carbonate films surrounding olivine grains. Considering the spatial resolution of $\mu \mathrm{CT}$ only the large melt blobs are identified, nevertheless they can be tracked in-situ with a time-resolution of few seconds for dynamics studies.

Kinetics of melt infiltration estimated from the time-lapsed CT-images (Figure 8) exhibit the diffusive dynamics of capillary flow with a decrease of flow rates with time, and a positive dependence on temperature. The observed vertical infiltration rates of $5.3-5.9 \mathrm{~mm} / \mathrm{h}$ confirm the high mobility of carbonate liquids relative to silicate ones, as already pointed out by Hammouda \& Laporte (2000). For comparison, Watson et al. (1982) reported infiltration rates of $\sim 0.05 \mathrm{~mm} / \mathrm{h}$ for basaltic silicate liquids under $\sim 1 \mathrm{GPa} \sim 1300{ }^{\circ} \mathrm{C}$, i.e. about two orders of magnitude slower. The present infiltration rates are slightly faster than the value of $2.5 \mathrm{~mm} / \mathrm{h}$ reported by Hammouda \& Laporte (2000) on sodium carbonate impregnation through a synthetic dunite. This may arise from the time resolution of the present in situ measurements that enables to capture the fast initial propagation front, while the infiltration rate is averaged over the duration of run in quench experiments of Hammouda \& Laporte (2000). Differences in initial porosity, and carbonate melt chemistry $\left(\mathrm{BaCO}_{3} \mathrm{vs} \mathrm{Na}_{2} \mathrm{CO}_{3}\right)$ may also have a significant effect.

The choice of $\mathrm{BaCO}_{3}$ carbonate as starting material was dictated by the need to enhance the X-ray absorption contrast of the liquid with the olivine matrix. Nevertheless this led to a carbonate liquid in strong disequilibrium with solid crystals, and hence to potential chemical exchanges between the $\mathrm{BaCO}_{3}$ melt and the matrix during the flow. This chemical reactivity was indeed observed on CTimages as rims of bright voxels surrounding specific grains (5-10 grains by average in each ROI) subsequently identified as pyroxene impurities on SEM images. Figure 12 shows the tracking of such a reaction rim and its growth over time, and highlights the fast kinetics of chemical reaction occurring at a time scale comparable with the melt flow. This points to the need of building reactive transport models for carbonatite migration in order to address the interplay between chemical reaction and the physics of melt transport. In this perspective, the extent of 4D microtomography imaging (e.g. Dobson et al., 2016) to extreme conditions opened by the UToPEc device offers an ideal approach for imaging these mass exchange processes. Though the spatial resolution is currently limited to $4-5 \mu \mathrm{m}$, 
which is significantly lower than the one achieved with electron imaging, and depends on the absorption contrasts within the studied material (Figure 11); it allows in situ observations with an unprecedented time-resolution for a quantitative understanding of reactive transport.

Figure 12 Tracking of the reaction rim surrounding a pyroxene grain in sample BaCarb1. Each caption represents the state of the process at a given time. Conditions are given in upper left corner.

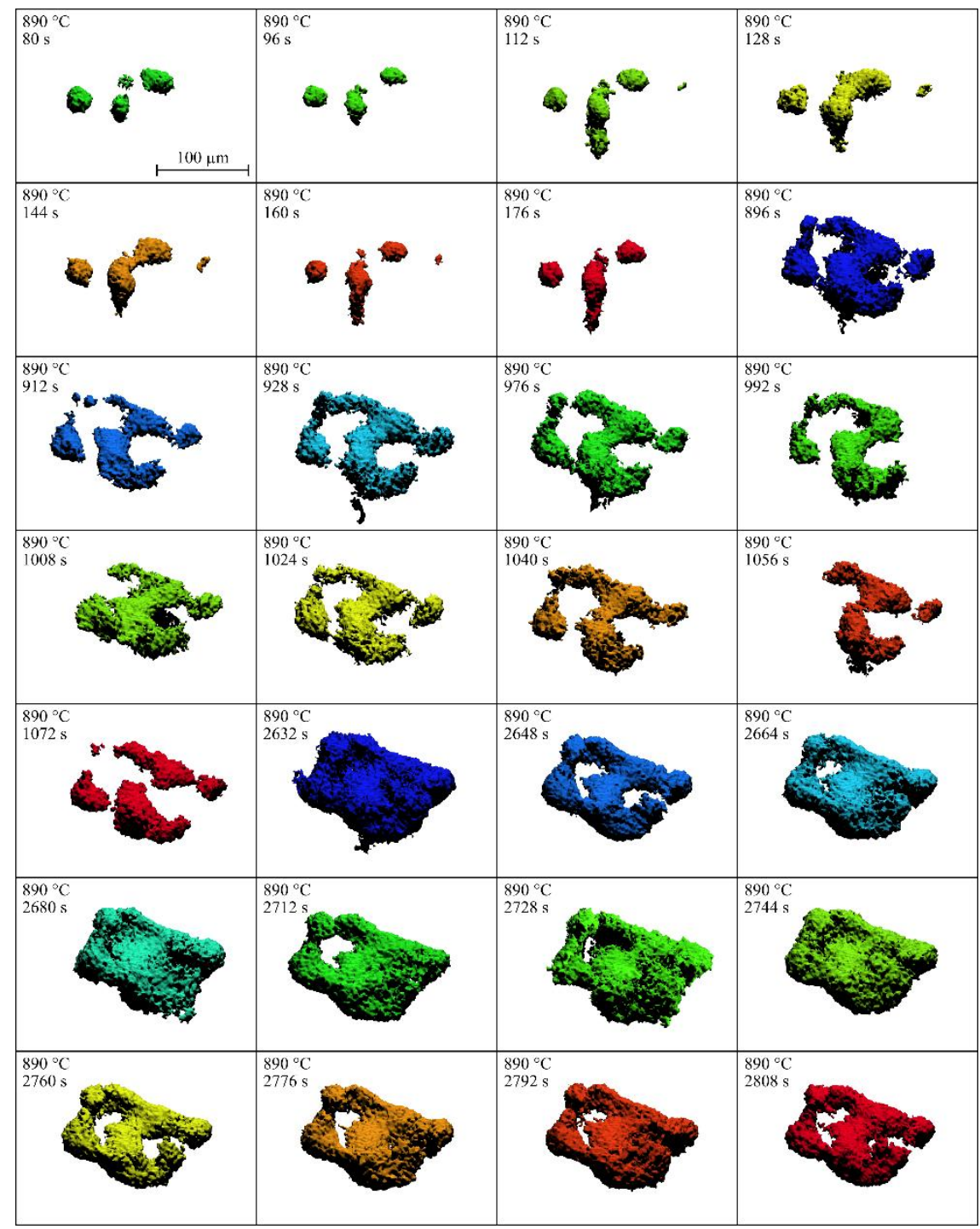

\section{Conclusion}

Here, we reported the experimental set-up developed at the PSICHE beamline of SOLEIL to perform high-speed XCT in the Ultra-fast Tomography Paris-Edinburgh cell (UToPEc) up to extreme conditions of $10 \mathrm{GPa}$ and $2000 \mathrm{~K}$. We provided a workflow for the acquisition, visualisation and quantification of CT-scans, accounting for the specificity of working in a high-pressure and temperature environment, and showed that alignment of time-lapsed $\mu \mathrm{CT}$ reconstructions allows investigation of 3D volumes, morphological statistics, and entity tracking through time. We illustrated the potential of this $4 \mathrm{D}$ tomography technique through the example of magma impregnation, which 
we were able to capture the capillary infiltration dynamics, under conditions of $\sim 2 \mathrm{GPa}$ and $\mathrm{T}>800^{\circ} \mathrm{C}$, with micrometric resolution and characteristic times of few seconds as we tracked the melt propagation front and the gradual porosity filling, as well as fast chemical reactions. This breakthrough in 4D tomography open new perspectives to explore the dynamics of phase transformations, reaction kinetics and microstructures, as well a porosity flows under extreme conditions.

Acknowledgements The UToPEc ongoing development program is supported by DIM OxyMORE Île de France, Synchrotron SOLEIL, and a CNRS-MITI grant. We thank G. Hamel, A. Prat and G.Morard for their collaboration on this project.

\section{References}

Álvarez-Murga, M., Perrillat, J. P., Le Godec, Y., Bergame, F., Philippe, J., King, A., Guignot, N., Mezouar, M. \& Hodeau, J. L. (2017). J. Synchrotron Radiat. 24, 240-247.

Boulard, E., Denoual, C., Dewaele, A., King, A., Le Godec, Y. \& Guignot, N. (2020). Acta Mater. 192, 30-39.

Boulard, E., King, A., Guignot, N., Deslandes, J.-P., Le Godec, Y., Perrillat, J.-P., Clark, A., Morard, G. \& Itié, J.-P. (2018). J. Synchrotron Radiat. 25, 818-825.

Dobson, D. P., Jones, A. P., Rabe, R., Sekine, T., Kurita, K., Taniguchi, T., Kondo, T., Kato, T., Shimomura, O. \& Urakawa, S. (1996). Earth Planet. Sci. Lett. 143, 207-215.

Dobson, K. J., Coban, S. B., McDonald, S. A., Walsh, J. \& Atwood, R. (2016). . CC. 27.

Green, D. \& Wallace, M. (1988). Nature. 336, 459-462.

Guignot, N., King, A. \& Boulard, E. (2020). J. Appl. Phys. 127, 240901.

Hammouda, T. \& Laporte, D. (2000). Geology. 28, 283-285.

pco.dimax HS4. PCO AG, Germany, https ://www. pco. de/highs peed-camer as/pcodi max-hs4/. A. 07 F. 2021

Hunter, R. H. \& McKenzie, D. (1989). Earth Planet. Sci. Lett. 92, 347-356.

King, A., Guignot, N., Deslandes, J.-P., Pelerin, M., Joosten, I., De Looff, D., Li, J., Bertrand, L., Rosenberg, E., Dewaele, A., Boulard, E., Le Godec, Y., Perrillat, J.-P., Giovenco, E., Morard, G., Weitkamp, T., Scheel, M., Perrin, J., Chevreau, H. \& Itié, J.-P. (2019). Integrating Mater. Manuf. Innov. 8, 551-558.

Klotz, S., Hamel, G. \& Frelat, J. (2004). High Press. Res. 24, 219-223.

Kono, Y., Kenney-Benson, C., Hummer, D., Ohfuji, H., Park, C., Shen, G., Wang, Y., Kavner, A. \& Manning, C. E. (2014). Nat. Commun. 5, 5091.

Le Godec, Y., Martinez-Garcia, D., Mezouar, M., Syfosse, G., Itié, J.-P. \& Besson, J.-M. (2000). High Press. Res. 17, 35-46. 
Liu, H., Wang, L., Xiao, X., De Carlo, F., Feng, J., Mao, H. -k. \& Hemley, R. J. (2008). Proc. Natl. Acad. Sci. 105, 13229-13234.

Maire, E. \& Withers, P. J. (2014). Int. Mater. Rev. 59, 1-43.

Mao, W. L., Lin, Y., Liu, Y. \& Liu, J. (2019). Engineering. 5, 479-489.

Mirone, A., Brun, E., Gouillart, E., Tafforeau, P. \& Kieffer, J. (2014). Nucl. Instrum. Methods Phys. Res. Sect. B Beam Interact. Mater. At. 324, 41-48.

Paganin, D., Mayo, S. C., Gureyev, T. E., Miller, P. R. \& Wilkins, S. W. (2002). J. Microsc. 206, $33-$ 40.

Perrillat, J. P. (2008). Mineral. Mag. 72, 683-695.

Philippe, J., Le Godec, Y., Mezouar, M., Berg, M., Bromiley, G., Bergame, F., Perrillat, J. P., Alvarez-Murga, M., Morand, M., Atwood, R., King, A. \& Régnier, S. (2016). High Press. Res. 36, 512-532.

Renard, F., Cordonnier, B., Dysthe, D. K., Boller, E., Tafforeau, P. \& Rack, A. (2016). J. Synchrotron Radiat. 23, 1030-1034.

Stevenson, D. J. (1986). Geophys. Res. Lett. 13, 1149-1152.

Turpin, L., Roux, S., Caty, O. \& Denneulin, S. (2020). Fundam. Informaticae. 172, 203-219.

Urakawa, S., Terasaki, H. P., Funakoshi, K., Uesugi, K. \& Yamamoto, S. (2010). J. Phys. Conf. Ser. 215, 012026.

Wang, Y., Uchida, T., Westferro, F., Rivers, M. L., Nishiyama, N., Gebhardt, J., Lesher, C. E. \& Sutton, S. R. (2005). Rev. Sci. Instrum. 76, 073709.

Washburn, E. W. (1921). Phys. Rev. 17, 273-283.

Watson, E. B., Sneeringer, M. A. \& Ross, A. (1982). Earth Planet. Sci. Lett. 61, 346-358.

Yu, T., Wang, Y. \& Rivers, M. L. (2016). Prog. Earth Planet. Sci. 3, 17. 